\title{
The tipping point: unanticipated dangers of operating room table position changes
}

\author{
Mazin Albert, DO • Arup De, MD, MBA (D)
}

Received: 21 July 2017/Revised: 1 August 2017/Accepted: 10 August 2017/Published online: 18 August 2017

(c) Canadian Anesthesiologists' Society 2017

\section{To the Editor,}

Four hours into a bilateral breast reconstruction, we experienced a near catastrophe when the electronically remote controlled, hydraulic operating room table was noted to be teetering on its front legs. Induction and maintenance of general endotracheal anesthesia had been uneventful in our otherwise healthy patient with a body mass index (BMI) of $28 \mathrm{~kg} \cdot \mathrm{m}^{-2}$. The surgical table was maintained in a normal, non-reversed, neutral position until the surgeon's request for "beach chair position" to assess breast appearance and symmetry. The surgical table was adjusted using the handheld remote with "head up" and "legs down" positioning to the surgical team's approval. No resistance was noted from the surgical table during these adjustments.

Unnoticed by the anesthesia and nursing personnel, however, the foot end of the table had rotated onto the forced hot air warming unit that was positioned underneath the table (Figure). This created a fulcrum with the warming unit, lifting the entire base of the surgical table off the
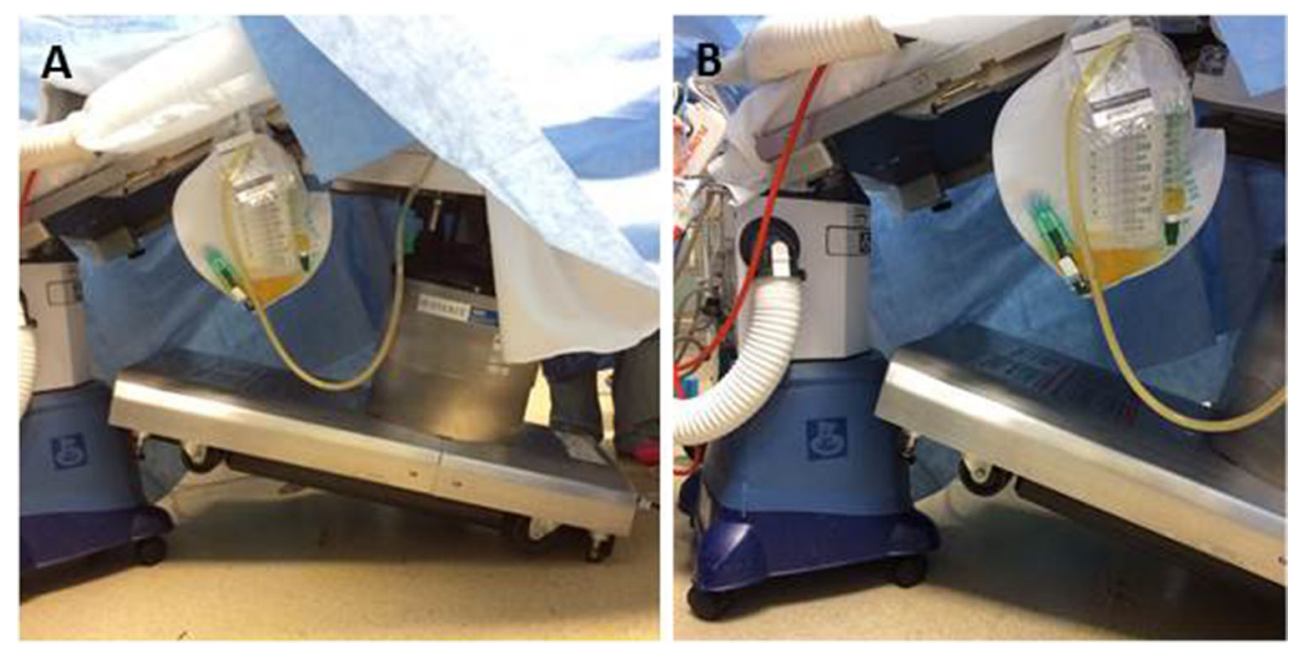

Figure Panel A) Operating table as noted by the circulating nurse, with the table's lower section wedged onto the forced air warming device. Panel B) Close-up photograph shows the degree of elevation of the table base that had not been noted previously

M. Albert, DO - A. De, MD, MBA $(\bowtie)$

Department of Anesthesiology, Albany Medical Center, Albany,

NY, USA

e-mail: dea@mail.amc.edu 
ground by 8 inches. Further adjustments to the surgical table, including flexing and reverse Trendelenburg brought the surgical table to a near tipping point, where any further "legs down" motion would cause the table and the patient to teeter over the front table legs that were still grounded. This could have caused severe patient (and anesthesia provider) injury.

A circulating nurse called attention to the odd-appearing table base. Upon evaluating the situation, the operation was halted temporarily, and a team of six additional operating room staff was assembled to support the table on all sides. Raising the legs of the table slowly while the table was fully supported by the team, the warming device was removed, and the patient and table were lowered.

Prior to the widespread use of electronic surgical tables, older anesthesia providers would remember the foot pedals and hand cranks that were required to position anesthetized patients. Although cumbersome and unwieldy, the manual controls required the user to get physically close to the table base and could detect any positioning or equipment issues that would prevent proper table function. Newer electronic tables can generate much greater force without the user noticing any difference. Although these electronic tables have safety algorithms that are supposed to prevent an incident such as the one described here, clearly the algorithms are not infallible.
Although there are limited reports of near-miss incidents associated with unlocking of surgical tables with higherBMI patients, ${ }^{1,2}$ we found nothing in the literature similar to this case. Anesthesia providers should always survey the top of the surgical field during adjustments of the surgical table, as well as the underside of the table, to ensure that potential obstacles and hazards are removed. As technological advances make our lives easier, we must remain vigilant to ensure that the same technology does not remove the tactile connections required for patient safety.

Conflicts of interest None declared.

Editorial responsibility This submission was handled by Dr. Philip M. Jones, Associate Editor, Canadian Journal of Anesthesia.

\section{References}

1. Booth RT, McAllister RK, Bittenbinder TM. Table tipping and a near-miss fall after unlocking a surgical table holding a morbidly obese patient. Proc Bayl Univ Med Cent 2016; 29: 145-6.

2. Razavian $S$, Thurn J. On the tipping point of disaster: operating room surgical table tips with obese patients. APSF Newsletter 2013; 28: 23-4. 